\title{
Comunicação e saúde nos manuais dos organismos internacionais para situações de emergência e desastre: intervenção e hegemonia
}

Luciana Lindenmeyer ${ }^{(a)}$

Carla Macedo Martins ${ }^{(b)}$

Lindenmeyer L, Martins CM. Communication and health in international organizations' manuals for emergency and disaster situations: intervention and hegemony. Interface (Botucatu). 2015; 19(53):299-310.

The paper analyzes international organizations' discourse on health communication in emergency and disaster situations, starting from two manuals: one produced by the World Health Organization (WHO) and another by the Pan-American Health Organization (PAHO). The analysis focuses on the actions of these organizations, as determined through the logic of 'intervention', which tends to erase the social inequalities that are produced through society's form of capital, both nationally and globally. This logic is expressed in the manuals through the notions of 'population', 'emergency and disaster' and 'communication'. The paper concludes by indicating that the following discursive-ideological effects are produced: disconnection between emergency and disaster and social life; legitimation of inequality between nations; disengagement of the nation state in relation to inhuman social health conditions; and linear and instrumental perspectives on communication.

Keywords: Discourse analysis. Ideology. Hegemony. International organizations. Health manuals.
O artigo analisa o discurso dos organismos internacionais sobre comunicação em saúde na situação de 'emergência e desastre', a partir de dois manuais, um produzido pela Organização Mundial de Saúde (OMS), outro pela Organização Panamericana de Saúde (OPAS). A análise considera a atuação destes organismos como determinada pela lógica da 'intervenção', que tende a apagar as desigualdades sociais produzidas pela forma societária do capital em âmbito nacional e mundial. Tal lógica se expressa, nos manuais, nos sentidos de 'população', 'emergência e desastre' e 'comunicação'. O artigo conclui indicando que são produzidos os seguintes efeitos discursivo-ideológicos: uma desconexão entre a emergência e o desastre e a vida social; uma legitimação da desigualdade inter-nações; uma desresponsabilização do Estado nacional em relação às condições sociais de saúde desumanas; e uma perspectiva linear e instrumental da comunicação.

Palavras-chave: Análise do discurso. Ideologia. Hegemonia. Organismos internacionais. Manuais de saúde.

\footnotetext{
(a) Serviço de Gestão do Trabalho, Instituto de Comunicação e Informação Científica e Tecnológica em Saúde, Fundação Oswaldo Cruz (Fiocruz). Av. Brasil, 4365, Pavilhão Haity Moussatché, sala 211, Manguinhos. Rio de Janeiro, RJ, Brasil. 21040-360. luciana.linden@icict. fiocruz.br

(b) Pós-Graduação em Educação Profissional em Saúde, Escola Politécnica de Saúde Joaquim Venâncio, Fiocruz. Rio de Janeiro, RJ, Brasil. cmartins@fiocruz.br
} 


\section{Introdução}

A dominação de cunho capitalista em um contexto mundializado, expressa na ideia de 'intervenção' e sustentada ou legitimada pelos organismos internacionais, tem sido amplamente discutida pela literatura. A lógica da intervenção tem sido problematizada, inclusive, na sua articulação com o discurso da defesa dos direitos humanos, considerado na sua versão acrítica, em que tanto 'intervenção' quanto 'direitos humanos' tendem a justificar as relações de subordinação entre nações ou blocos de nações'.

Em paralelo, a questão da comunicação como espaço scioeconômico de produção de relações de poder, na era da indústria cultural e da política mediatizada, atravessa a literatura crítica sobre a contemporaneidade, que afirma a comunicação como um espaço contraditório, tanto de reprodução das formas hegemônicas do capital ${ }^{2}$ quanto de disputa e luta na direção de uma sociedade que supere a desigualdade ${ }^{3}$. O campo da comunicação e saúde ${ }^{4}$ não se situa à parte deste contexto, sendo também condicionado, inerentemente, pelas características de uma sociedade não igualitária ${ }^{5}$.

O presente artigo se inscreve nesta discussão sobre as formas societárias hodiernas produzidas e reproduzidas pelo campo da comunicação e saúde, tomada em um contexto de formas de dominação amplamente mundializadas. Nesta direção, o artigo tem como objetivo analisar o discurso sobre comunicação e saúde em manuais de emergência e desastres produzidos por dois organismos internacionais de saúde, ou seja, Organização Mundial de Saúde (OMS) e Organização Panamericana de Saúde (Opas).

A análise demonstra, em última instância, que a lógica da intervenção dos organismos internacionais de saúde, no campo da comunicação, se constrói a partir de processos discursivosideológicos que buscam, em alguma medida, apagar e legitimar as desigualdades inerentes ao capitalismo. Para tal, o discurso destes organismos internacionais define e (re)significa noções e categorias centrais ao trabalho em comunicação e saúde, como 'população' e situações de 'emergência e desastre', assim como da própria concepção de comunicação.

No primeiro item do artigo, apresentamos o conceito gramsciano de hegemonia, buscando situar os meios de comunicação na sociabilidade do capital. No segundo, discutimos as conquistas e tensões na comunicação e saúde, problematizando a concepção linear e instrumental que atravessa o campo. No terceiro, enfocamos os organismos internacionais no capitalismo contemporâneo, voltando-nos para aqueles atuantes diretamente no campo da saúde (OMS e Opas). No quarto, apresentamos os pressupostos teórico-metodológicos para a análise dos manuais enfocados, estes últimos sendo objeto, por sua vez, do quinto, sexto e sétimo itens. Nas considerações finais, apontamos o conjunto de discussões críticas que a análise abre no que tange à formação do comunicador em saúde.

\section{Comunicação e hegemonia}

O processo de dominação na sociedade capitalista é tratado, na obra de Antonio Gramsci, com referência no conceito de hegemonia. Para Gramsci,

O exercício 'normal' da hegemonia, no terreno tornado clássico do regime parlamentar, caracteriza-se pela combinação da força e do consenso, que se equilibram de modo variado, sem que a força suplante em muito o consenso, mas, ao contrário, tentando fazer com que a força pareça apoiada no consenso da maioria, expresso pelos chamados órgãos da opinião pública - jornais e associações [...]. ${ }^{6}$ (p. 95)

É relevante enfatizar que a perspectiva gramsciana de hegemonia se dá na própria produção da sociabilidade, que tem a comunicação, em inúmeras dimensões, como um espaço crucial na contemporaneidade. É também importante observar, para os fins de nossa análise, que o conceito não se restringe à análise no âmbito dos Estados nacionais, mas constitui, de fato, uma forma de produção social que se dá, inclusive, na relação entre nações ou regiões. Nas palavras do autor, "Toda relação de 'hegemonia' é necessariamente uma relação pedagógica, que se verifica não apenas no interior de 
uma nação, entre diversas forças que compõem, mas em todo o campo internacional e mundial, entre conjuntos de civilizações nacionais e continentais"7 (p. 399).

A área de comunicação, na América Latina e no Brasil, não tem ignorado a tradição gramsciana, reafirmando a perspectiva de que a hegemonia, como um processo contínuo e complexo, se relaciona à capacidade de um determinado bloco em articular um conjunto de fatores que pode levá-lo a dirigir, moral e culturalmente, e de modo sustentado, a sociedade como um todo ${ }^{8}$.

Para a compreensão de tais processos na totalidade da produção da sociabilidade, faz-se necessário, ainda, nos remetermos à articulação entre 'Estado' e 'sociedade civil'. Para Gramsci,

\begin{abstract}
[...] podem-se fixar dois grandes 'planos' superestruturais: o que pode ser chamado de 'sociedade civil' (isto é, o conjunto de organismos designados vulgarmente como 'privados') e o da 'sociedade política ou Estado', planos que correspondem, respectivamente, à função de 'hegemonia' que o grupo dominante exerce em toda a sociedade e àquela de 'domínio direto' ou de comando, que se expressa no Estado e no governo 'jurídico'.? (p. 20-1)
\end{abstract}

Em outras palavras, para Gramsci, o Estado utiliza também, para manutenção do status quo, a partir da sociedade civil, os chamados aparelhos privados de hegemonia ${ }^{9}$, apontando para a construção de uma concepção de mundo em favor dos segmentos sociais dominantes. Ademais, a perspectiva de Gramsci, inclusive com o desdobramento posterior do conceito de Estado ampliado' ${ }^{9}$, supõe uma forma mais dinâmica e dialética de análise dos movimentos de reprodução e transformação social, em que Estado e a chamada sociedade civil não estão em oposição: nem o Estado é o espaço unicamente da dominação, nem a sociedade civil é o espaço da liberdade.

Não é nossa proposta, no âmbito deste artigo, mapear os movimentos atuais em torno do tema comunicação e democracia no âmbito da saúde. Contudo, é inevitável apontar a centralidade do tema no contexto brasileiro, por exemplo, nas recentes discussões sobre o Marco Civil da Internet (sobre a qual o campo da saúde no Brasil tem se posicionado, por exemplo, por intermédio da Associação Brasileira de Saúde Coletiva ${ }^{10}$ ) ou, ainda, nas novas formas de organização e participação política a partir da mídia denominada alternativa, em contraponto à oligopolizada ${ }^{11}$.

Em suma, identificamos a comunicação e os meios de comunicação (de massa) como poderosos espaços de produção de hegemonia. Oriundos de processos de natureza contraditória, tais meios são, ao mesmo tempo, também produtores de contra-hegemonia, conforme indicado na dinâmica de movimentos contestatórios atuantes no campo da comunicação e saúde, tratado no item a seguir.

\title{
Comunicação e saúde
}

Nossa análise considera a comunicação como estruturante das políticas públicas em saúde, inclusive por sua estreita articulação com a promoção ${ }^{12}$. Seguindo a definição proposta por Araújo e Cardoso ${ }^{4}, 0$ campo "trata da comunicação nos processos de elaboração, implantação e gestão de políticas públicas nos domínios onde se requer uma ação pública, incluído, aí, o da saúde" (p. 22). Por esta razão, fazse necessário discutir as concepções hegemônicas sobre comunicação e suas implicações na produção coletiva e política do conhecimento em saúde.

Torres $^{13}$ indica que o campo da comunicação e saúde no Brasil tem sido palco de disputas de sentido, que se expressam em termos epistemológicos, isto é, na própria concepção de comunicação. Para a autora, a comunicação - na sua interface com a saúde - é ainda fortemente pautada, por sua utilização estratégica, para informar e para persuadir, buscando apenas promover mudanças comportamentais. A autora relaciona tal prática a uma concepção ou um modelo caracterizado como: desenvolvimentista, instrumental, informacional e transferencial. Esta constatação não elide o fato de que, pelo volume de discussões deste campo no contexto brasileiro, a comunicação e saúde tem sido resgatada na sua dimensão dialógica, ou seja, como fato de mediação e de alteridade, contrapondo-se aos modelos positivistas de comunicação nos termos mencionados.

Araújo e Cardoso ${ }^{4}$ seguem esta linha de crítica, ao apontarem que o modelo linear e polarizado, que busca excluir o equívoco como 'ruído', influenciou a abordagem específica na área da saúde. 
Neste contexto, a escuta e o diálogo tendem a não existir, ficando, somente, o emissor com direito de voz e expressão.

Podemos afirmar, concordando com os autores mencionados, que o modelo de dois polos é o predominante no campo da comunicação, com contornos superficiais de incorporação do diálogo. Permanece a ideia fundamental de produção da informação para ser transmitida, de forma linear, de um emissor a um receptor, com desigualdade entre ambos ${ }^{14}$.

Tal crítica ao campo da comunicação e saúde não ignora o conjunto de lutas que marca o setor. Como é amplamente reconhecida, a criação do Sistema Único de Saúde (SUS) é fundamentada nos princípios básicos de universalidade, integralidade e equidade, com ênfase na participação popular e na estruturação da rede de serviços de saúde, de forma descentralizada, regionalizada e hierarquizada. A partir dessa conquista, poderia se compreender a comunicação como forma de aperfeiçoar o sistema de saúde, estimulando a participação popular na efetivação desses princípios. Em particular, após a criação do SUS, destacamos a $12^{a}$ Conferência Nacional de Saúde ${ }^{15}$, que contou com uma importante participação da população e que apresentou, entre seus principais eixos temáticos, a comunicação e informação em saúde. Neste contexto, contudo, deve-se reiterar que persiste a necessidade de se ampliar o debate, apontada por Pitta ${ }^{16}$, ainda na década passada, em função de uma ausência de definição de políticas governamentais de comunicação, inclusive, na relação com as instituições democráticas na América Latina.

Retomando a análise do campo em um contexto mais global e, em particular, latino-americano, referimo-nos ao trabalho de Rojas-Rajs e Soto ${ }^{5}$. Para os autores, a comunicação em saúde - ou 'para a saúde' - constitui um campo ainda em construção, pois seu impulso decisivo se originou a partir da década de 1980, e sua afirmação, como campo acadêmico, ocorreu apenas na década de 1990. O caráter recente do campo justificaria o conjunto de análises e estudos, que se restrigem a indicar a precariedade das estratégias, metodologias e avaliações do campo, assim como a marcar a relevância de considerar as perspectivas e os modos de vida dos destinatários da comunicação ${ }^{5}$. $\mathrm{Na}$ ausência de uma perspectiva que recupere a complexidade dos processos de determinação social, o próprio campo pode reproduzir as desigualdades em saúde, "ao considerar que o simples fato de possuir informações possibilita às pessoas tomar decisões distintas sobre sua saúde e forma de viver" ${ }^{5}$ (p. 589).

Ou seja, articulam-se o paradigma comunicacional hegemônico e as concepções de saúde que elidem as determinações histórico-sociais. Em outras palavras, há uma estreita relação entre formas de dominação e modelo comunicacional, numa sociedade estruturada em termos de desigualdade e de classes sociais, inclusive, entre nações.

\section{Organismos internacionais e saúde}

Em linhas gerais, a relação entre os países centrais, periféricos e os organismos internacionais é pautada pela perspectiva ideológica de que os países considerados desenvolvidos têm o conhecimento, a intenção e a experiência necessários para elaborar proposições no sentido de que os demais países alcancem, também, o mesmo patamar de desenvolvimento. Apaga-se, neste percurso, que as diferenças históricas, econômicas, políticas, culturais e sociais - produzidas pelas próprias contradições do capitalismo - são entraves estruturantes para as iniciativas de intervenção aplicadas às nações.

Além disso, não se colocam em questão os ideais de progresso, desenvolvimento e civilização hegemônicos, que acabam funcionando como legitimação de políticas de dominação sobre estes países, muitas vezes, sob a capa da defesa dos direitos humanos e de um ideal de democracia anistórico e eurocêntrico ${ }^{1,7,17,18}$.

A OMS, criada em 1948, pode ser identificada como uma agência internacional que, para influenciar, monitorar e avaliar as políticas de saúde em todo o mundo, emprega a cooperação técnica e científica como principal estratégia ${ }^{19}$. Em 1902, foi criada a Opas, por meio da Convenção Sanitária Internacional, sendo reconfigurada no contexto de Guerra Fria pós-Segunda Guerra. Neste sentido, pode-se compreender a atuação da OMS em termos da "saúde global" como parte da perspectiva de que a globalização econômica e as forças de mercado produziriam a homogeneização da riqueza e do desenvolvimento; e estas mudanças econômicas contribuiriam para o desaparecimento dos 'egoísmos 
nacionais' e para a construção de um governo democrático e global, responsável pela paz dos mercados e dos povos $^{20}$.

Assim, observa-se uma tendência de que trajetórias históricas de dominação e exploração entre nações sejam apagadas, reproduzindo a perspectiva ideológica de que o desenvolvimento homogêneo é possível, desde que sejam aplicadas medidas consideradas eficazes e pontuais.

Por fim, voltando ao estudo de Rojas-Rajs e Soto ${ }^{5}$, é de se observar que, no âmbito da Opas e da OMS, a perspectiva de saúde como uma dimensão individual (e não social) se relaciona com a lógica de enfocar a população como consumidor (de produtos e serviços de saúde) e como receptor (de informações no campo da comunicação e saúde). Portanto, podemos supor que, na atuação dos organismos internacionais, concepções de saúde, modelos de comunicação e formas de relações sociais encontram-se imbricados, reiterando a articulação entre política, modelos comunicacionais e formas de dominação contemporâneas, tratadas no item anterior.

\section{Análise discursiva dos manuais (OMS e Opas)}

$\mathrm{Na}$ área da saúde e, em particular, no âmbito das políticas públicas de comunicação e saúde, guias, cartilhas e manuais podem ser considerados como um dos balisadores da prática profissional. Os textos produzidos e divulgados, provenientes de organismos internacionais, além de organizarem o trabalho, apresentam um objetivo instrucional evidente.

Em particular, podemos afirmar que os manuais constituem, hoje, um importante material didático e uma ferramenta de gestão do trabalho, assim como um espaço de produção discursivo-ideológica. Especificamente em relação à comunicação e saúde, estes materiais de saúde podem atuar na afirmação de determinadas formas de comunicação e na legitimação das políticas públicas de saúde em curso ${ }^{21}$.

Compuseram o corpus da pesquisa os dois únicos manuais produzidos pelos organismos internacionais de saúde cujas temáticas tratavam do objeto delineado, por ocasião da configuração e organização do material de análise (2010-2011).

O primeiro, intitulado manual 'Comunicação eficaz com a mídia durante emergências de saúde pública', foi traduzido e publicado pela Editora do Ministério da Saúde, em 2009, em português, tendo sido publicado, originalmente, pela OMS em 2007. Na página da ficha catalográfica, constam dois autores (Randall N. Hyer e Vincent T. Covelho). São descritos, como público-alvo, o pessoal de campo (escritórios) da OMS, que não estaria familiarizado com a mídia, os agentes de saúde pública e os comunicadores de saúde pública. Este manual é organizado em torno de sete passos para se alcançar o objetivo de comunicação eficaz com a mídia. O texto apresenta, ainda, inúmeros quadros, tabelas e modelos com as indicações a serem seguidas pelos profissionais e conteúdos no treinamento de equipes ${ }^{22}$.

O segundo manual analisado foi 'Gestión de la Información e Comunicación en emergencias y desastres', publicado pela Opas, em 2009, somente em inglês e espanhol. Trabalha-se, nesta pesquisa, com a versão em espanhol de autoria da própria Opas. Na página de Agradecimentos, é mencionado que o conteúdo é resultado de intenso processo de participação e consulta regional. Identificou-se, neste, um direcionamento mais específico para o que chamam de "equipes de resposta aos desastres", "mas também aos profissionais nacionais ou internacionais de comunicação e informação que tenham interesse ou trabalhem em ações de preparação ou de resposta a desastres no setor saúde" 23 (p. 8).

A análise dos manuais segue a orientação teórico-epistemológica da análise do discurso franco-brasileira ${ }^{24}$. Tal orientação implica que consideremos estes materiais como espaços políticos contraditórios que legitimam, produzem e fazem emergir sentidos sob a lógica da sociabilidade hegemônica, embora não deixem de ser espaço e objeto de luta social.

Assim, enfocamos o discurso como um campo de disputa, no caso, atrelado às políticas de saúde em curso e a outros processos de reprodução e transformação social. O processo de reprodução se expressa, sobretudo, pela noção de ideologia, que, na análise do discurso, se traduz pela 'evidência de sentido' 24 - ou seja, pela produção discursiva da obviedade de significado, remetendo, em última instância, à (suposta) impossibilidade de uma forma de sociabilidade diferente da capitalista. 
Ademais, para a $A D$, por sua inscrição teórica no marxismo e na psicanálise, a evidência de sentido aponta, contraditoriamente, para o não-dito: aquilo que se tenta silenciar, mas cuja emergência se dá exatamente neste processo.

Como ruptura e superação - de natureza ontológica e epistemológica - das teorias idealistas e positivistas produzidas pela Linguística, a AD está longe de se limitar ao estabelecimento de procedimentos metodológicos. A rigor, a AD se oporia ao estabelecimento de metodologias fetichizadas, que isentariam o analista do trabalho interpretativo, histórico e ideológico da língua. Em outras palavras,

[...] Análise do Discurso é um campo de pesquisa que não possui uma metodologia pronta. Isso significa que ao lançar mão [...] do arcabouço teórico, [...] o analista estará ao mesmo tempo alçando os dispositivos metodológicos. [...] Desse modo, as pesquisas neste viés possuem sempre um caráter qualitativo-interpretativista. Não há análise quantitativa de dados. Buscase, no geral, realizar uma 'exaustividade vertical' como dispositivo analítico [...] considerando os objetivos da pesquisa, que podem incluir os efeitos de memória, da história, as ideologias, as heterogeneidades constitutiva e mostrada, os não-ditos. [...] Na AD, a metodologia de análise não consiste em uma leitura horizontal, ou seja, em extensão, do início ao fim do texto, tentando compreender o que o mesmo diz, uma vez que todo texto é incompleto. Mas, realizase uma análise em profundidade, que é possibilitada pelo batimento descrição-interpretação em que se verifica, por exemplo, posições sujeito assumidas, imagens e lugares construídos a partir das regularidades discursivas evidenciadas nas materialidades. ${ }^{25}$ (p. 62)

Esta matriz epistemológica apontou para a análise do discurso dos manuais em seu papel na (re)produção e consenso social - portanto, nos processos de hegemonia -, enfocando as noções relacionadas à sociedade, saúde e comunicação também como efeitos ideológicos.

A 'exaustividade vertical' possibilitou, assim, formular a discussão dos manuais em foco a partir dos sentidos de: 'população'; 'emergências e desastres'; e 'comunicação'. As duas primeiras noções constituem a base das próprias ações propugnadas nos manuais, ou seja, que grupos sociais serão considerados 'em risco', e o que define uma situação como excepcional. Estas duas categorias se articulam para produzirem um discurso que atua na naturalização e legitimação de determinadas perspectivas sobre a comunicação e saúde e, consequentemente, sobre a própria instituição políticoideológica do campo, o que explica seu destaque na nossa análise.

\section{População}

Uma primeira categoria de análise é, portanto, 'população'. Partindo desta categoria, podemos afirmar que se observa um discurso que suscita o controle da informação e participação nos processos da comunicação em saúde. Este aspecto pode ser observado a partir da caracterização e definição da população nos manuais, delineadas com o objetivo de adequar a comunicação e a gestão da informação a públicos-alvo específicos.

Assim, em trecho do manual da OMS, as 'populações especiais' são apresentadas como uma das limitações com que a mídia pode se deparar no processo da comunicação eficaz:

Jornalistas são quase sempre mal preparados para atender às necessidades de informação de populações especiais durante emergências relacionadas à saúde. Eles também podem não ver como o seu trabalho ou papel comunicar diretamente com estes públicos. Populações especiais incluem as pessoas idosas, portadores de deficiências, sem teto, pessoas confinadas em suas casas, minorias raciais e culturais, minorias lingüísticas, analfabetos, populações transitórias (por exemplo, turistas, viajantes a negócios e trabalhadores migratórios) e populações encarceradas. Porque os veículos de comunicação de massa adaptam seus conteúdos para alcançar grupos demográficos particulares, é papel dos órgãos de saúde pública transmitir sua mensagem para as mais variadas audiências pelos mais diferentes canais possíveis. Isto inclui audiências 
especiais, que não podem ou não irão receber, entender ou agir de acordo com a mensagem da saúde pública. ${ }^{22}$ (p. 29)

Conforme se pode constatar, as populações especiais se referem a conjuntos que representam grandes quantidades de grupos sociais, pois, quando se unificam pessoas idosas, sem teto, portadores de deficiência, minorias raciais, as minorias deixam de ser quantitativamente minoritárias na contemporaneidade. Seria o caso, inclusive, de explicitar o não-dito: quem estaria incluído como população 'não especial' e a que parcela da sociedade esta categorização se refere?

A não-definição destas categorizações das parcelas da sociedade - a partir do rótulo supostamente neutro de 'população especial' - recobre conflitos e desigualdades. Não se trata de um equívoco técnico-linguístico, e sim de construção do discurso e da ideologia calcada no não-dito e na evidência de sentido. O que se apaga é que a população especial não constitui uma exceção, mas resulta de uma forma de sociabilidade, em que a vulnerabilidade é, na verdade, massiva.

Em outras palavras, o objetivo de buscar controlar o que é divulgado e apresentado para a população não é per se problemático. Na verdade, em situações de epidemia, por exemplo, a divulgação descontrolada das informações pode gerar culpabilização dos doentes pela população; como consequência, os atingidos tendem a não reportar a doença ou a não se dirigir às instituições de saúde responsáveis, agravando o quadro epidêmico.

O que está em questão aqui são os sentidos construídos em torno do que subjaz a estas formas de controle, no caso, a própria definição da exceção em termos de 'população especial'. Tal categoria tende a apagar os processos de produção social da (falta de) saúde e, portanto, legitima o descompromisso com a garantia dos direitos (de saúde). Contraditoriamente, os manuais, em alguma medida, ao buscarem garantir a qualificação dos quadros e o estabelecimento de normas de atuação profissional, promovem, também, a naturalização da desigualdade - e da intervenção pontual como única solução.

\section{Emergências e desastres}

No que tange às noções de emergência e desastre, observam-se dois movimentos discursivoideológicos: num primeiro plano, a tentativa de silenciar o político; num segundo plano, a legitimação da desobrigação por parte do Estado em cuidar de problemas de saúde pública previsíveis, passíveis de serem alvo de medidas de prevenção, com investimentos e ações permanentes, de forma a minimizar os denominados riscos.

No manual da OMS, consta a definição de emergência como "uma situação séria, inesperada e potencialmente perigosa que demanda ação imediata" ${ }^{24}$ (p. 17). No manual da Opas, não há definição para desastre ou emergência. $\mathrm{O}$ da $\mathrm{OMS}^{24}$ apresenta, ainda, um quadro com as causas de emergência em saúde pública, que, em tradução livre, seriam:

Ponto de informação - Causas de emergências de saúde pública

- Agentes de risco de transmissão respiratória;

- Agentes de risco de transmissão por alimentos;

- Agentes de risco de transmissão pela água;

- Agentes de risco de transmissão por vetores;

- Agentes infecciosos desconhecidos;

- Agentes de risco químicos;

- Materiais tóxicos;

- Agentes de risco biológicos; e

- Material radioativo.

Emergências podem também aparecer rapidamente como resultado de:

- Desastres naturais;

- Atividades militares;

- Atividades terroristas; 
- Revoluções políticas;

- Acidentes, incidentes ou explosões em indústrias ou usinas nucleares que causem ferimentos, mortes, dano de propriedade e perdas econômicas;

- Investigação de mídia que descobre ações erradas;

- Vazamentos oficiais de informações sigilosas;

- Brechas de segurança (deliberadas ou acidentais); e

- Escândalos..$^{24}$ (p. 97)

Para iniciarmos nossa análise destas concepções, é necessário recuperar o conceito ampliado de saúde, em sua historicidade, resultante da luta do conjunto de trabalhadores, incluindo os de saúde. Desta forma, hoje, pode-se concordar que:

Em sentido amplo, a saúde é a resultante das condições de alimentação, habitação, educação, renda, meio ambiente, trabalho, transporte, emprego, lazer, liberdade, acesso e posse da terra e acesso aos serviços de saúde. Sendo assim, é principalmente resultado das formas de organização social, de produção, as quais podem gerar grandes desigualdades nos níveis de vida. ${ }^{26}$ (p. 4)

Todavia, quando um manual voltado para treinar os comunicadores na área da saúde caracteriza inúmeras situações como emergência, pode-se questionar como estas podem ser compatíveis com o primeiro conceito de emergência, definido, no mesmo texto, como 'situação séria e inesperada'. Um 'risco químico' é 'inesperado', se considerarmos a atual escalada tecnológica do capitalismo? Uma 'revolução política' é para ser tratada como algo a ser combatido, como um 'desastre'? Ou ainda: 'atividades militares' e 'atividades terroristas' constituem, hoje, exceção na lógica de um mundo que permanece polarizado?

O manual da Opas, mesmo não apresentando uma definição explícita de emergência ou desastre, aponta na mesma direção a respeito das situações que devem sofrer intervenção, como emergências de saúde pública. Ou seja, o que deve ser tratado como prioridade (como emergência) em saúde pública, é definido, em conjunto, pelos organismos internacionais e pelos Estados nacionais.

Cabe destacar que, desta forma, uma situação previsível, porém não totalmente evitável, como um desastre natural (terremoto), é colocada no mesmo patamar de uma situação prevenível (como epidemias de dengue). Assim, a produção social da saúde fica apagada nesta formulação. Em última instância, silencia-se a sociabilidade que explica as condições precárias de existência, assim como justifica-se a falência do Estado - e, consequentemente, sua desresponsabilização - em resolver situações correntes de agravos à saúde, na medida em que estariam na ordem do incontrolável e do não-humano. Ou seja, 'intervenção' e 'desresponsabilização do Estado', neste caso, produzem, também, um efeito ideológico-discursivo que naturaliza a produção histórica das condições precárias de vida.

O segundo movimento discursivo - a legitimação da desobrigação, por parte do Estado, em cuidar de problemas de saúde pública previsíveis - se expressa na transferência de responsabilidade para o âmbito da sociedade civil, tratada, no texto da OPAS, no que diz respeito à busca de ajuda externa, cuja tradução livre é:

Aos atores humanitários tradicionais - como as agências das Nações Unidas e o Movimento da Cruz Vermelha - se somam cada vez mais organizações não governamentais com uma grande capacidade logística e de mobilização de recursos. Os doadores, quer sejam privados ou públicos, individuais ou corporativos, também tem aumentado e diversificado sua participação. ${ }^{23}$ (p. 48)

Numa forma social cindida em classes, seguindo a perspectiva gramsciana, podemos afirmar que os aparelhos privados de hegemonia e seus mecanismos de financiamento não são neutros: neste caso, eles tendem a buscar reproduzir a lógica na qual um conjunto de problemas sociais, 
incluindo os de 'saúde', são tratados como exceções ou emergenciais. O manual contribui para este processo, na medida em que produz os sentidos até aqui analisados e coloca, de forma positiva, tais aparelhos no cenário decisório da gestão da saúde, inclusive, lado a lado das organizações de caráter governamental.

Em suma, a concepção de emergências e desastres, nos manuais analisados, apaga o caráter histórico e social da produção da saúde, seja por figurar conflitos sociais, como 'atividades terroristas', 'revoluções políticas' e 'atividades militares', como situações de exceção, seja por naturalizar uma suposta impossibilidade de um tratamento público, pelo Estado, das questões coletivas de saúde.

\title{
Comunicação
}

Observa-se, nos manuais analisados, um tratamento da produção e circulação do conhecimento que tende a estabelecer uma sinonímia entre comunicação e 'emissão de mensagens', e que aponta para um apagamento da informação como uma relação social.

Um primeiro trecho a ser ressaltado, na análise da concepção de comunicação nos manuais em foco, ocorre na introdução do manual da $\mathrm{OMS}^{22}$, como nota de rodapé. Esta esclarece que o termo 'comunicação' é entendido como "um meio de enviar ou receber informações. Também - o processo pelo qual informação é trocada entre grupos ou indivíduos por sistemas mutuamente compreendidos de linguagens, símbolos, sinais ou comportamentos" (p. 17).

Procura-se, assim, estabelecer uma concepção de comunicação dialógica, que envolve troca. Todavia, a análise sugere que essa definição e concepção de comunicação não se sustenta. Se estabelecermos um diálogo entre os dois manuais, podemos destacar um trecho do manual da OPAS, quando este apresenta que uma das responsabilidades das equipes de resposta é de "coordenar as ações de divulgação e distribuição oportuna e eficiente da informação" 23 (p. 17), o que entra em contraponto com o segmento anteriormente destacado no outro manual.

Com a multiplicação das formas impulsionadas pelas tecnologias de informação e comunicação, os meios de comunicação têm incorporado algumas estratégias que indicam o 'diálogo' com o público; contudo, essas estratégias acabam se resumindo, por exemplo, a pesquisas para votar o que se deseja assistir na programação ou fazer comentário sobre programas com formato preestabelecido pelas corporações midiáticas. Estas estratégias não apontam uma real possibilidade de participação popular, estando tal impossibilidade condicionada por uma desigualdade na produção da informação, da comunicação e do saber. Reiteramos que, neste contexto, a teoria emissor-receptor não desapareceu.

Centrando nossa análise no manual da OMS, destacamos uma referência direta à necessidade da aplicação de uma concepção de comunicação como linear, pela referência à teoria do ruído:

\begin{abstract}
A preparação de todos os tipos de mensagem acima deve ser guiada por teorias e princípios da comunicação eficaz com a mídia. Por exemplo, 'a teoria do ruído mental' é uma das principais construções da literatura de comunicação em emergência. Esta teoria reconhece que quando as pessoas estão preocupadas elas freqüentemente têm dificuldades para compreender e lembrar-se das informações. Este efeito pode reduzir a habilidade da pessoa para processar informações em mais de $80 \%$, e o desafio para a comunicação de risco, desta forma, é: superar as barreiras que o ruído mental cria; produzir mensagens precisas para várias audiências em diversos contextos sociais e culturais; e alcançar o máximo de eficácia da comunicação dentro das restrições impostas pelo ruído mental. ${ }^{22}$ (p. 78)
\end{abstract}

Por fim, ainda sobre a concepção de comunicação, destaca-se, já no manual da OPAS, o capítulo que trata dos meios de comunicação. O capítulo é apresentado da seguinte forma ${ }^{23}$, em tradução livre do original:

4. Como trabalhar com os meios de comunicação?

4.1 Os meios de comunicação durante as emergências e desastres

4.2 Entendendo os meios de comunicação? 
$4.3 \mathrm{O}$ que buscam os meios?

4.4 Como chegar aos meios? ${ }^{23}$ (p. 61)

Os meios de comunicação, neste caso, são apresentados de forma fetichizada, dotados de vida própria e formulados de modo independente da produção social. Inevitável nos remetermos aqui a outro mecanismo discursivo-ideológico que atravessa a sociabilidade capitalista: a personificação do 'mercado'. Ou seja, neste caso, os grandes oligopólios da comunicação deixam de ter proprietário e passam a existir com uma vida autônoma, independente das relações sociais efetivamente produzidas pelos homens; neste contexto, nada mais evidente do que se adaptar a estes meios.

Em suma, um ponto crucial aqui consiste em apontar que a comunicação dialógica requer, dialeticamente, uma mudança estrutural na sociedade, onde quem fala e quem escuta estejam em igualdade social. Esta contradição é apagada nos manuais em foco.

\section{Considerações finais}

O artigo almejou analisar o discurso sobre comunicação e saúde em manuais de emergência e desastres produzidos por dois organismos internacionais de saúde (OMS e Opas). A partir da análise, podemos afirmar que, nos manuais mencionados, as noções de 'população', 'emergências e desastres', e 'comunicação' são destituídas de seu caráter histórico, social e político e, portanto, também o são as situações de saúde, pelos processos discursivos que têm como efeito ideológico a tentativa de apagamento da realidade social da cisão de classe.

Como conclusão, podemos indicar que são produzidos os seguintes efeitos discursivo-ideológicos nos manuais analisados: uma desconexão entre a emergência e o desastre e a vida social; uma legitimação da desigualdade inter-nações; uma desresponsabilização do Estado nacional em relação às condições sociais de saúde desumanas; e uma perspectiva linear e instrumental da comunicação.

Em linhas gerais, podemos afirmar, portanto, que os manuais contribuem para a desconexão entre saúde e produção da vida social. As concepções de comunicação desempenham papel relevante neste processo, na medida em que os manuais, embora explicitem uma busca pela reversão do paradigma unilinear e transferencial, reproduzem, em grande medida, nos termos analisados no artigo, tais modelos hegemônicos.

Contraditoriamente, ao buscarem aperfeiçoar os vínculos de comunicação com a população, reproduzem e naturalizam as formas de desigualdade social, nas quais se incluem os modelos hegemônicos de comunicação. Em última instância, tais contradições expressam a dinâmica dos processos de dominação em jogo no campo da comunicação e saúde, nos quais a disputa permanece aberta, porém sob a lógica das determinações da sociabilidade capitalista.

Neste contexto, em que a população tende a ser reduzida à condição de receptora de informações de saúde esvaziadas de sua dimensão política, apontamos a necessidade de aprofundar a discussão sobre as concepções de qualificação e trabalho reproduzidas e produzidas no material em questão, na medida em que estes são escritos na perspectiva de ocuparem, também, uma função formativa. Uma pesquisa futura deveria analisar, portanto, tais manuais à luz das relações entre capitalismo e as teorias hodiernas de formação profissional, enfocando, em particular, a ideologia das 'competências', já que esta aponta para uma perspectiva comportamentalista do humano, em coerência com o modelo comunicacional dominante, discutido no presente artigo.

\section{Colaboradores}

Luciana Lindenmeyer se responsabilizou pela configuração do corpus. Carla Macedo Martins trabalhou em conjunto nas demais etapas de produção do manuscrito. 


\section{Referências}

1. Wallerstein I. O universalismo europeu: a retórica do poder. São Paulo: Boitempo; 2007.

2. Martín-Barbero J. Dos meios às mediações: comunicação, cultura e hegemonia. Rio de Janeiro: UFRJ; 2009.

3. Moraes D. A batalha da mídia: governos progressistas e políticas de comunicação na América Latina e outros ensaios. Rio de Janeiro: Pão e Rosas; 2009.

4. Araujo IS, Cardoso JM. Comunicação e saúde. Rio de Janeiro: Fiocruz; 2007.

5. Rojas-Rajs SO, Soto EJ. Comunicación para la salud y estilos de vida saludables: aportes para la reflexión desde la salud colectiva. Interface (Botucatu). 2013; 17(46):587-99.

6. Gramsci A. Cadernos do cárcere: Maquiavel, notas sobre o estado e a política. 3a ed. Rio de Janeiro: Civilização Brasileira; 2007. v. 3.

7. Gramsci A. Cadernos do cárcere: os intelectuais. O princípio educativo. Jornalismo. 3a ed. Rio de Janeiro: Civilização Brasileira; 2004. v. 2.

8. Moares D. A batalha da mídia: governos progressistas e políticas de comunicação na América Latina e outros ensaios. Rio de Janeiro: Pão e Rosas; 2009.

9. Coutinho CN. Gramsci: um estudo sobre seu pensamento político. 3a ed. Rio de Janeiro: Civilização Brasileira; 2007.

10. Moção aprovada no VI Congresso Brasileiro de Ciências Sociais e Humanas em Saúde: a saúde coletiva e marco civil da internet [Internet]. Rio de Janeiro: Abrasco; 2013 [acesso 2013 Nov 23]. Disponível em: http://redeaps.enviodenews.com/registra clique. php?id=H\% 7C515605\% 7C168633\% 7C20678\&url=http\% 3A\% 2F\% 2Fwww.abrasco. org.br\%2Fnoticias\%2Fnoticia_int.php\%3Fid_noticia\%3D1704

11. Lima V. Mídia, rebeldia urbana e crise de representação. In: Maricato $E$, Brito $F$, Vainer $C$, Viana $S$, lasi $M L$, Davis $M$, et al. Cidades rebeldes: passe livre e as manifestações que tomaram as ruas do Brasil. São Paulo: Boitempo; 2013.

12. Paulino FO. Comunicação e saúde. Brasília (DF): Casa das Musas; 2009.

13. Torres MM. Campo da comunicação \& saúde no Brasil: mapeamento dos espaços de discussão e reflexão acadêmica [dissertação]. Rio de Janeiro (RJ): Instituto de Comunicação e Informação Científica e Tecnológica em Saúde, Fundação Oswaldo Cruz; 2012.

14. Mattelart A, Mattelart M. História das teorias de comunicação. São Paulo: Loyola; 1999.

15. Ministério da Saúde. Conselho Nacional de Saúde. Seminário de comunicação, informação e informática em saúde. 2a ed. Brasília (DF): MS; 2005.

16. Pitta AMR, Magajewski FRL. Políticas nacionais de comunicação em tempos de convergência tecnológica: uma aproximação ao caso da saúde. Interface (Botucatu) [Internet]. 2000 [acesso 2013 Out 23 ]; 4(7):61-70. Disponível em: http://www.scielo. $\mathrm{br} /$ scielo.php?script $=$ sci_arttext\&pid $=\mathrm{S} 1414-32832000000200005 \& \operatorname{lng}=\mathrm{pt} \& \mathrm{nrm}=\mathrm{iso}$. http://dx.doi.org/10.1590/S1414-32832000000200005

17. Amin Ash. Para uma exposição sobre o aumento da influência do institucionalismo sobre a área das políticas regionais. SI: sn; 1999.

18. Anderson B. Comunidades imaginadas: reflexões sobre a origem e a expansão do nacionalismo. Lisboa: Edições 70; 2005.

19. Matta GC. A organização mundial de saúde: do controle de epidemias à luta pela hegemonia. Trab Educ Saude. 2005; 3(2):371-96. 
20. Fiori J. Sistema mundial, América do Sul, África e "potências emergentes". Rev Eletr Com Inf Inov Saude [Internet]. 2010 [acesso 2013 Nov 23]; 4(1):3-18. Disponível em: http://www.reciis.icict.fiocruz.br/index.php/reciis/article/view/350/516. DOI: 10.3395

21. Martins C, Stauffer A. Sobre a produção da sociabilidade capitalista: o discurso sobre trabalho, comunicação e participação nos manuais dos agentes comunitários de saúde. Rev Eletr Com Inf Inov Saude [Internet]. 2012 [acesso 2013 Nov 23]; 6(4). Disponível em: http://www.reciis.icict.fiocruz.br/index.php/reciis/article/viewArticle/669/1265

22. Organização Mundial de Saúde. Comunicação eficaz com a mídia durante emergências de saúde pública: um manual da OMS. Brasília (DF): Ministério da Saúde; 2009.

23. Organização Pan-Americana da Saúde. Gestión de la información y comunicación en emergências y desastres: guia para equipos de respuesta. Panamá: OPAS; 2009.

24. Orlandi E. Análise de discurso: princípios e procedimentos. Campinas: Pontes; 1999.

25. Marques W. Metodologia de análise do discurso face aos novos suportes mediáticos. Dom Lingu@gem Rev Eletr Ling [Internet]. 2011 [acesso 2014 Out 20]; 4(1):58-73. Disponível em: http://www.seer.ufu.br/index.php/dominiosdelinguagem

26. Ministério da Saúde. Anais da $8^{a}$ Conferência Nacional de Saúde; 17-21 mar 1986; Brasília, Brasil. Brasília (DF): MS; 1986.

Lindenmeyer L, Martins CM. Comunicación y salud en los manuales de los organismos internacionales para situaciones de emergencia y desastre: intervención y hegemonía. Interface (Botucatu). 2015; 19(53):299-310.

El artículo analiza el discurso de los organismos internacionales sobre comunicación en salud en la situación de 'emergencia y desastre' a partir de dos manuales: uno producido por la Organización Mundial de la Salud (OMS), otro por la Organización Panamericana de Salud (OPAS). El análisis considera la actuación de estos organismos como determinada por la lógica de la 'intervención' que tiende a apagar las desigualdades sociales producidas por la forma societaria del capital en ámbito nacional y mundial. Tal lógica se expresa en los manuales, en los sentidos de 'población', 'emergencia y desastre' y 'comunicación'. El artículo concluye indicando que se producen los siguientes efecto discursivo-ideológicos: una desconexión entre la emergencia y el desastre y la vida social, una legitimación de la desigualdad inter-naciones, una des-responsabilización del Estado nacional en relación a las condiciones sociales de salud deshumanas y una perspectiva lineal e instrumental de la comunicación.

Palabras clave: Análisis del discurso. Ideología. Hegemonía. Organismos internacionales. Manuales de salud. 